IZA DP No. 6460

Pro-Social Missions and Worker Motivation: An Experimental Study

Sebastian Fehrler

Michael Kosfeld

April 2012 


\title{
Pro-Social Missions and Worker Motivation: An Experimental Study
}

\author{
Sebastian Fehrler \\ University of Zurich \\ and IZA
}

Michael Kosfeld

Goethe University Frankfurt, CEPR, CESifo and IZA

Discussion Paper No. 6460
April 2012

IZA

P.O. Box 7240

53072 Bonn

Germany

Phone: $+49-228-3894-0$

Fax: +49-228-3894-180

E-mail: iza@iza.org

\begin{abstract}
Any opinions expressed here are those of the author(s) and not those of IZA. Research published in this series may include views on policy, but the institute itself takes no institutional policy positions.

The Institute for the Study of Labor (IZA) in Bonn is a local and virtual international research center and a place of communication between science, politics and business. IZA is an independent nonprofit organization supported by Deutsche Post Foundation. The center is associated with the University of Bonn and offers a stimulating research environment through its international network, workshops and conferences, data service, project support, research visits and doctoral program. IZA engages in (i) original and internationally competitive research in all fields of labor economics, (ii) development of policy concepts, and (iii) dissemination of research results and concepts to the interested public.
\end{abstract}

IZA Discussion Papers often represent preliminary work and are circulated to encourage discussion. Citation of such a paper should account for its provisional character. A revised version may be available directly from the author. 
IZA Discussion Paper No. 6460

April 2012

\section{ABSTRACT \\ Pro-Social Missions and Worker Motivation: An Experimental Study}

Do employees work harder if their job has the right mission? In a laboratory labor market experiment, we test whether subjects provide higher effort if they can choose the mission of their job. We observe that subjects do not provide higher effort than in a control treatment. Surprised by this finding, we run a second experiment in which subjects can choose whether they want to work on a job with their preferred mission or not. A subgroup of agents (roughly one third) is willing to do so even if this option is more costly than choosing the alternative job. Moreover, we find that these subjects provide substantially higher effort. These results suggest that relatively few workers can be motivated by missions and that selection into mission-oriented organizations is important to explain empirical findings of lower wages and high motivation in the latter.

JEL Classification: C92, J33, M52

Keywords: motivation, effort provision, contract choice, sorting, lab experiment

Corresponding author:

Sebastian Fehrler

University of Zurich

Affolternstrasse 56

8050 Zurich

Switzerland

E-mail: sebastian.fehrler@pw.uzh.ch 
Well, then, says I, what's the use you learning to do it right when it's troublesome to do right and ain't no trouble to do wrong, and the wages is just the same?

Huckleberry Finn (in Mark Twain 1885)

Many individuals are motivated to exert effort because they care about their jobs, rather than because there are monetary consequences for their actions.

Candice Prendergast (2007, p.180)

\section{Introduction}

Plenty of evidence suggests that there are workers who care about the mission of their job. Recent survey studies, for example, show that workers in the public sector care about the usefulness of their job for society (Frank and Lewis 2004), and that altruistic motivation is an important motive for volunteering (see, e.g., Burns et al. 2006 or Carpenter and Knowles Myers 2010) 1 . Analyzing British Household Panel data, Gregg et al. (2011) find that workers in the non-profit sector are more likely to do unpaid overtime work than workers in the for-profit sector, and Fehrler (2010) shows that teachers in Swiss Waldorf schools, private schools with a special pedagogic profile, strongly identify themselves with their schools' mission and accept to work for far lower wages than public school teachers. Nyborg and Zhang (2011) present evidence which suggests that some workers in the private sector care about the mission of their employer, too. Analyzing data on Norwegian firms, they find that the firm's reputation for social responsibility is associated with lower wages, controlling for many other factors.

How mission induced motivation affects principal agent problems has been studied in a number of theoretical papers ${ }^{2}$ In several of these studies, public sector workers are modeled as agents who care about the mission of their jobs (e.g., Francois 2000, Dixit 2002, and Prendergast 2007). Dixit (2002) concludes that agencies could save on monetary incentives to get the same level of effort as private sector firms. Extending this idea to other sectors, Besley and Ghatak (2005) develop a model in which workers provide more effort if they are matched with an employer with their preferred mission, which in turn makes it optimal for the employers to lower monetary performance incentives and offer different contracts.

\footnotetext{
${ }^{1}$ For a recent comprehensive review of empirical studies on public sector motivation see Perry (2010).

${ }^{2}$ For a review of this literature see Delfgaauw and Dur (2008).
} 
In their model, employer missions and performance pay are perfect substitutes. They also discuss policy implications and conjecture that the decentralization of a school market, for example, might lead to a substantial gain in efficiency through better matches of teachers and school profiles.

In this study we ask the question whether any workforce could potentially be motivated to provide more effort with the right mission. If so, employers might be able to save on monetary incentives. We test this hypothesis in a laboratory labor market experiment, in which the subjects can choose their job mission. We test whether they provide higher effort and whether this has an effect on contract choice. Our implementation of job missions follows Besley and Ghatak's (2005) model, in which some workers care about the output of their job. In our mission choice treatment, agents generate a donation to an NGO of their choice. In our control treatment, subjects generate an extra pay-off to a randomly drawn student from the students register of the University of Zurich. In the first group we, thus, have a simple matching mechanism of missions and motivations, while the total output generated under the same contract and effort choices is the same in both groups $3^{3}$ In each treatment, half of the subjects play the role of the employer and the other half the role of the worker. Employers offer contracts consisting of a fix wage and a piece rate. Then, workers choose their effort level which determines pay-offs and donations.

Our main results are the following. Workers do not provide higher effort in the mission choice than in the control treatment. In neither treatment effort provision is higher than the optimal effort provision of a purely self-interested worker. Consequently, employers cannot save on monetary incentives in the mission choice treatment and the contracts they offer are not different from those in the control treatment.

A related study, focusing on the motivations behind pro-social effort provision, finds similar evidence. Tonin and Vlassopoulos (2010) measure effort provision in a real effort task in a field experiment, in which subjects generate a donation for an NGO of their choice in addition to their own pay-off. They find a slightly higher effort provision than in a control treatment. However, the effect is very small and only significant for female participants.

These experimental findings and the empirical evidence of motivated workers in missionoriented organizations, discussed above, seem contradictory. However, it might be the case that selection of a few mission motivated workers into according jobs explains the observations. If there are only few workers who can be motivated, employers with strong missions have an incentive to screen workers. Paying lower wages than the market wage is a pos-

\footnotetext{
${ }^{3}$ The level of the donation is varied between different sub-treatments.
} 
sible screening mechanism for worker motivation (Delfgaauw and Dur 2007, Brekke and Nyborg 2008) $4^{4}$

To study selection, we run a second experiment in which all subjects are workers. They are offered two contracts each period by the experimenter. The contracts in the first periods all pay the same piece rate but differ in their fix wage. Under one contract in each period the workers can generate a donation to an NGO of their choice in addition to their own income. Under the second contract they generate a donation to a randomly chosen student. By varying the difference in the fix wages between the two contracts we can measure how much a subject is willing to pay to work for their preferred NGO.

We observe that only about one third of the subjects choose the NGO contract when it is costly to do so (even if the cost is minimal). This group, however, provides higher effort than the other subjects and their effort provision is higher than the optimal effort level of a purely self-interested worker 5

Overall, these results suggest that the scope for increases in effort of a given workforce through the provision of missions is small. However, a relatively small motivated subgroup of workers exists and self-selects into the mission-oriented jobs. Offering low salaries appears to work as a screening device for motivated workers.

The paper proceeds with the theoretical background in section 2, followed by the experimental design in section 3 , the presentation of the results in section 4 , and the conclusion in section 5 .

\section{Theoretical Framework}

Consider the following model which is based on Besley and Ghatak (2005). There are employers and workers. Every worker is matched with an employer who offers them a contract under which they work and choose their effort input.

The employer wants to maximize profit $\Pi$ :

\footnotetext{
${ }^{4}$ Delfgaauw and Dur (2007), and Brekke and Nyborg (2008) model labor market sorting with motivated and unmotivated (purely self-interested) workers and employers with different missions who can offer different contracts to attract workers. In a similar way, Kosfeld and von Siemens (2011) study labor market sorting in a model with workers who have different preferences regarding cooperation and team work and firms with different corporate cultures.

${ }^{5}$ Further evidence in this direction comes from a recent experimental study that follows up on our experiments and tests effort provision of NGO employees. The latter provide higher effort in a treatment where they can generate a donation for their own organization, than in a treatment where they can generate a donation for a different, exogenously chosen charity (Gerhards 2012).
} 


$$
\Pi=Y-w
$$

which is the output $Y$ minus wage $\operatorname{costs} w$. Output depends on effort. The wage is determined by the contract parameters that are set by the employer and effort:

$$
\begin{aligned}
& Y(e)=10 e \\
& w(e)=p e+f,
\end{aligned}
$$

where piece rate $p$ and fix wage $f$ are the contract parameters. The worker's utility depends on their wage, their cost of effort and the generated (extra) output $D$ that goes to the mission of the job:

$$
\begin{aligned}
U(e, w) & =w(e)-C(e)+\theta D(e) \\
C(e) & =\frac{1}{4} e^{2} \\
D(e) & =k e
\end{aligned}
$$

with $\theta \geq 0.6$ If a motivated worker is matched with a principal with the right mission, $\theta$ is positive, while it is zero if the worker is purely self-interested or the employer does not have the right mission.

The optimal effort provision of purely self-interested workers, i.e., subjects with $\theta=0$, is twice the piece rate:

$$
\arg \max _{e}\left(p e-\frac{1}{4} e^{2}\right)=2 p .
$$

Given this optimal response to an offered contract, the optimal choice of contract is the solution to the following maximization problem of the employer:

$$
\arg \max _{p, f}\left(20 p-2 p^{2}-f\right) .
$$

The solution is $p=5$ and $f=0$. Under this contract the optimal effort level of a purely self-interested subject is $e=10$. However, if a subject values $D$ with weight $\theta>0$, effort provision changes to:

\footnotetext{
${ }^{6}$ Think, for example, about the production of a collective good, whose production costs and benefits are not completely reflected in the market price. $D$ would then be the additional (above market price) value that some workers might care about.
} 


$$
\arg \max _{e}\left(e(p+k \theta)-\frac{1}{4} e^{2}\right)=2(p+k \theta) .
$$

A motivated worker, thus, provides more effort under the same contract. Therefore, the employer has an incentive to lower the piece rate to:

$$
\arg \max _{p}(20 p-2 p(p+k \theta))=5-\frac{1}{2} k \theta .
$$

Because of this effect, improved matching of motivated workers and employers with the right missions can increase overall output.

\section{Experimental Design}

We implement the mission of a job as a donation to an NGO that subjects can generate in addition to their monetary pay-offs. The level of the donation depends linearly on effort as in (6). $k \in\{1,3\}$ is varied between sub-treatments.

As a small increase in effort decreases own income less than it increases the donation, it is more efficient to do so rather than to maximize own income and donate later. Under any contract with $p=5$, for example, a deviation from the optimal response 10 by 1 (to 11) costs 0.25 points but creates an increase of the donation of 1 point in the sub-treatments with $k=1$, and even by 3 points in the sub-treatments with $k=3$. Another increase of effort by 1 (to 12 ) further increases the donation by 1 or 3 points and costs 0.75 points.

\section{Experiment I}

This experiment has two main treatments. In both, half of the subjects are assigned to the role of employers, the other half to the role of workers. In the mission choice treatment, the workers choose an NGO from a list of 16, at the beginning of the experiment, for which they can later generate a payment in addition to their personal payoff] 7 Every worker is randomly matched with an employer. These pairs are not changed for the whole experiment which consists of 10 periods. The sequence of actions is as follows. The employer offers a contract consisting of a piece rate $p$, which has to be an integer from the interval [0,12], and

\footnotetext{
${ }^{7}$ The list of NGOs is: Caritas Switzerland (a Christian charity), Amnesty International, Médecins Sans Frontièrs, The International Red Cross, Swissaid, Attac, UNICEF, Terre des Hommes, Brot für Alle (a Christian aid organization), Kindernothilfe Schweiz (an organization to help children in need), Aids-Hilfe Schweiz (an organization to help HIV patients), Krebsliga Schweiz (an organization to help cancer patients), Greenpeace, Tierschutzbund (animal rights protection), WWF, and the Heilsarmee (Salvation Army).
} 
a fix wage $f$ (integer from $[0,100]$ ). Then, the worker chooses an effort level $e$ (integer from $[0,18])$. Workers do not have the option to reject a contract but can choose to provide zero effort which leads to an output of zero. The output, the wage that the employer has to pay, and effort costs of the worker are given by (2), (3), and (5). A base income of 15 is given to the workers to get roughly the same payoffs for workers and employers under contract and effort choices close to the optimal choices for purely self-interested workers and employers. The worker's pay-off is $15+f+p e-C(e)$. As the marginal costs of effort are increasing, the slope of the cost-of-effort function equals the piece rate at some point, and there is an interior solution for the optimal effort level for most piece rates. As the choice of effort is restricted, corner solutions are optimal for very high piece rates and a piece rate of zero.

The level of the donation to the NGO depends on the effort the workers provide. In treatment M-low, the donation is equal to the effort level $e(k=1)$, in treatment M-high it triples to $3 e(k=3)$. After ten periods the incomes from all periods are summed up and paid out. Donations are paid out to the NGOs after all sessions are completed.

For the control treatments C-low and C-high the set up is almost the same. The only difference is that subjects do not generate a donation to an NGO but an extra payoff to a randomly selected student from the University of Zurich. The reason to include a payoff to a third party in the control treatment is to keep the sum of all payments, generated under the same choices, the same between treatment and control group 8 There are two treatment groups in which payoffs of level $e$ (C-low) and $3 e$ (C-high) to the randomly selected student are generated. To allow for learning, we chose to keep the pairs of employers and workers fix for the ten periods, which gives the employers a chance to see how their workers respond to the contract parameters, and to adapt their contract offers accordingly.

All subjects receive a show up fee of 10 CHF. Every point is worth 5 Rappen (.05 CHF). A total of 270 subjects participated in Experiment I, which was conducted in the Laboratory for Experimental and Behavioral Economics at the University of Zurich. Students earned on average 31.8 CHF. Each session lasted for about 90 minutes.

\section{Experiment II}

In this experiment, all subjects start by choosing an NGO from the same list as in the mission choice treatment of Experiment I. After doing so, they play 20 periods, in each of

\footnotetext{
${ }^{8}$ In Experiment II, in which subjects can choose to generate a donation for either an NGO of their choice or a randomly selected student, no subject chooses the student option when it is more costly than the NGO option, which shows that no subject was strongly motivated by the donation to the student.
} 
which they are offered two contracts. Both contracts consist of a piece rate $p$ and a fix wage $f$. Under one of the two contracts the subject works for their chosen NGO, that is, their effort generates a donation to that NGO, on top of their income. Under the other contract the workers generate a donation to a randomly selected student of the University of Zurich. In both cases the donation is equal to the effort provision $e(k=1)$, which has to be an integer from the interval $[0,12]$, like in Experiment I. The subjects choose one contract each period and choose their effort level. The cost-of-effort function is again given by (5) and the payoff of the worker equals the wage given by (2).

The contracts that are offered all have the same piece rate, $p=5$, in the first periods. The fix wage for the NGO contract is unchanged in these periods as well $(f=20)$. The only parameter that is varied is the fix wage under the alternative contract. We start with a lower piece rate $(f<20)$ and then increase the piece rate from period to period, making it more and more costly to choose the NGO contract (for all the contract pairs see Table A2, Appendix). The periods with $p=5$ are of our main interest in this experiment. The remaining periods are added as a robustness check to see whether any potential differences in effort provision under the NGO and alternative contracts in the first periods are also observable with different piece rates (with $p=3$ and $p=7$ ). In the end, one of the periods is chosen randomly and subjects are paid out according to their choices in that period 9

In this experiment, all subjects receive a show up fee of $10 \mathrm{CHF}$, too. One point is worth 50 Rappen (.5 CHF). 70 subjects participated in Experiment II which was conducted in the Decision Science Lab at the ETH Zurich 10 Students earned, on average, 32.5 CHF and the sessions again lasted for about 90 minutes 11

\section{Results}

\section{Experiment I}

A look at the raw data from the treatments C-low and C-high shows that most workers choose effort levels around the optimal level for a purely self-interested worker. Figure 1 shows scatter plots of $p$ and $e$. As expected, we see that most observations in both subtreatments are close to the optimal effort level represented by the solid line. We do not see differences between the treatments with respect to the relative number of observations above

\footnotetext{
${ }^{9}$ We slightly changed the contract pairs in 4 of the 20 periods between the two sessions (see Appendix).

${ }^{10}$ Both labs recruit their students from the same subject pool.

${ }^{11}$ All treatments for both experiments were programmed with zTree (Fischbacher 2007).
} 
or below the line. A look at the average values for $p$ and $e$ (Table 1) shows that they lie close to the predicted values. The effort level $e$ in treatment C-high, however, is significantly lower than the optimal level of $2 p(p<.01$, t-test $)$.

Figure 1: Scatter Plots of $p$ and $e$ for Treatments C-low and C-high (Experiment I)
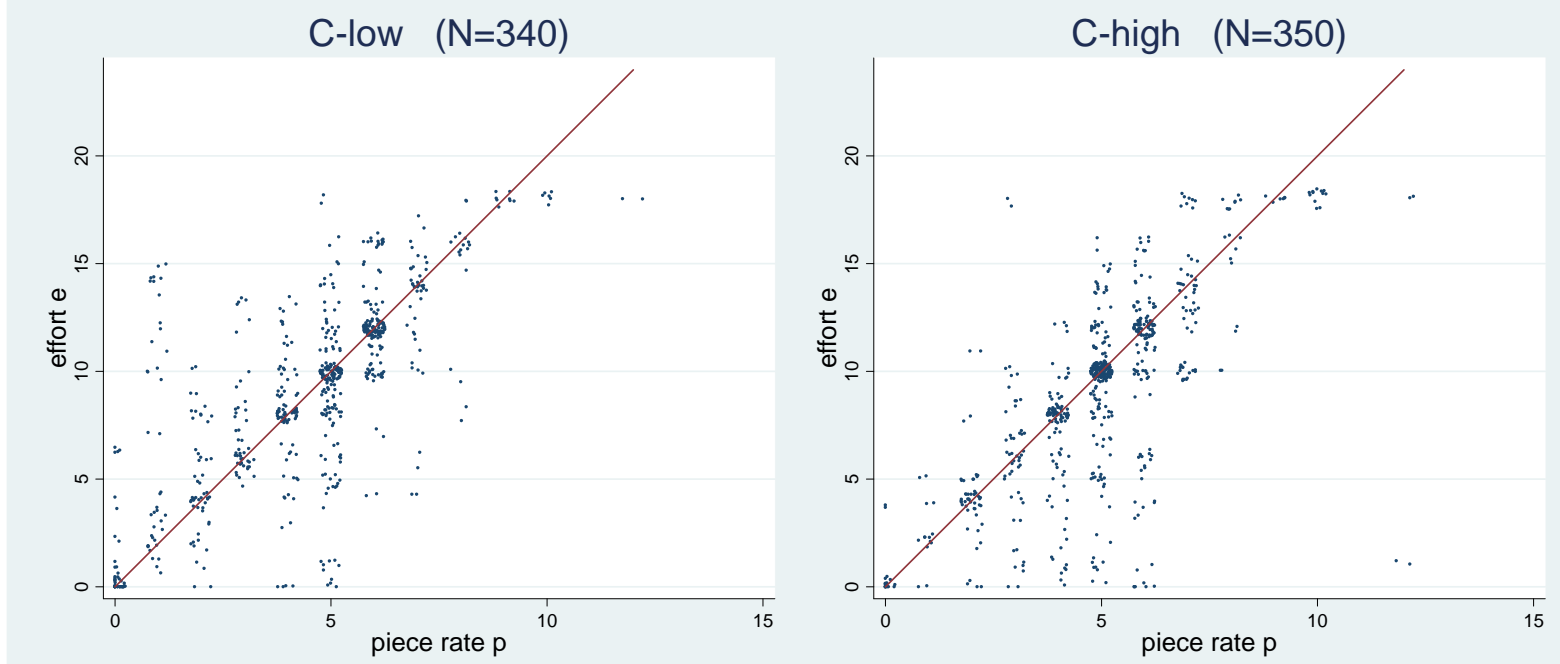

Note: The line is equal to $2 p$, the optimal effort for purely self-interested workers. $\mathrm{N}$ is the number of contracts, i.e., 10 times the number of worker-employer pairs. Dots are moved randomly to ovoid overlay.

Table 1: Averages of Contract and Effort Choices in Treatments C-low and C-high

\begin{tabular}{lrrrr}
\hline treatment & piece rate $p$ & effort $e$ & $e-2 p$ & $N$ \\
\hline C-low & $4.49(.18)$ & $9.11(.37)$ & $.14(.25)$ & 340 \\
C-high & $4.88(.11)$ & $9.02(.31)$ & $-.74(.25)$ & 350 \\
\hline
\end{tabular}

Note: Cluster adjusted standard errors in parentheses (each employerworker pair is one cluster). $N$ is the number of contracts (10 per workeremployer pair). $(e-2 p)$ is the difference between effort and optimal effort of a purely self-interested worker.

If many workers are motivated by their chosen mission in treatments M-low and M-high, as we expect, we should see different results in Figure 2 and Table 2. However, this is not the case. In treatment M-low and M-high, just as in treatment C-low, the effort provision is not statistically different from the optimal effort of a purely self-interested subject. Average 
effort provision in treatment M-low and M-high is significantly greater than in treatment C-high ( $p$-values $<.05, \mathrm{~F}$-Tests) but not different from treatment $\mathrm{C}$-low and to each other $(p$-values $>.8$, F-Tests $)$.

Figure 2: Scatter Plots of $p$ and $e$ for Treatments M-low and M-high (Experiment I)

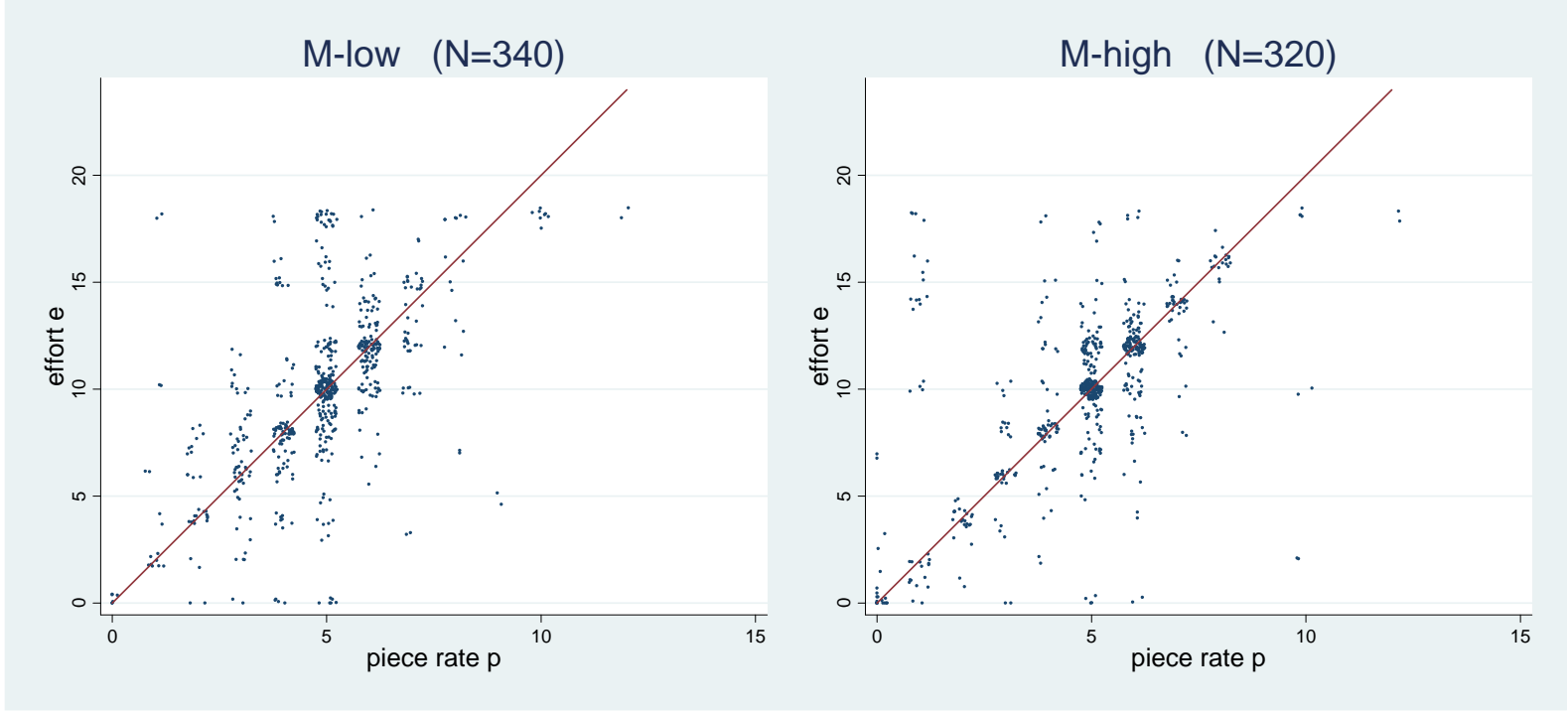

Note: The line is equal to $2 p$, the optimal effort for purely self-interested workers. $\mathrm{N}$ is the number of contracts, i.e., 10 times the number of worker-employer pairs. Dots are moved randomly to ovoid overlay.

Table 2: Averages of Contract and Effort Choices in Treatments M-low and M-high

\begin{tabular}{lrrrr}
\hline treatment & piece rate $p$ & effort $e$ & $e-2 p$ & $N$ \\
\hline M-low & $4.89(.11)$ & $9.92(.31)$ & $.14(.27)$ & 340 \\
M-high & $4.83(.19)$ & $9.89(.29)$ & $.23(.27)$ & 320 \\
\hline
\end{tabular}

Note: Cluster adjusted standard errors in parentheses (each employerworker pair is one cluster). $N$ is the number of contracts (10 per workeremployer pair). $e-2 p$ is the difference between effort and optimal effort of a purely self-interested worker.

These statistics provide no evidence that subjects in treatment M-low or M-high increase effort above the optimal level in order to increase the donation to their chosen NGO, and the result is robust if one looks at single periods of the experiment. We also ran a tobit regression of effort on piece rate and fix wage (see Table 3). The estimated coefficients for 
the piece rate lie between 1.72 and 2.04 for the different treatments. These coefficients are not significantly different from the optimal coefficient of 2 for somebody maximizing their own payoff and not different from each other (F-tests, $p$-values $>.05$ ). The coefficients for fix wage are very close together for all treatments, ranging from .07 to .13, and are all significantly different from zero (F-tests, $p$-values $<.05$ ).

Table 3: Tobit Regression for Experiment I

Dependent variable: effort $e$

M1

\begin{tabular}{lcc} 
& Coef & SE \\
\hline$p \times$ M-low & $2.04^{* * *}$ & .16 \\
$p \times$ M-high & $1.72^{* * *}$ & .15 \\
$p \times$ C-low & $1.91^{* * *}$ & .13 \\
$p \times$ C-high & $1.96^{* * *}$ & .18 \\
$f \times$ M-low & $.13^{* * *}$ & .03 \\
$f \times$ M-high & $.09^{* *}$ & .04 \\
$f \times$ C-low & $.11^{* * *}$ & .02 \\
$f \times$ C-high & $.07^{* * *}$ & .02 \\
M-low & -1.25 & .8 \\
M-high & .89 & .72 \\
C-low & -.4 & .68 \\
C-high & -1.07 & .74 \\
$\sigma$ & $3.00^{* * *}$ & .20 \\
\hline$N$ & 1350 \\
$N$ clusters & 135 \\
pseudo $R^{2}$ & .15 \\
\hline Note: $* p<.1, * * p<.05, * * * p<.01$. \\
$p \times(f \times)$ treatment denotes the interaction \\
term between piece rate $p($ fix wage $f)$ and \\
the treatment dummy. \\
\multicolumn{2}{l}{} \\
\hline
\end{tabular}

The results tell us that subjects do not provide higher effort than optimal for purely self-interested workers in any of the treatments. Consequently, the employers do not choose different contracts in the different settings. Experiment I, thus, provides no support for the 
hypothesis that a given workforce can be motivated to provide more effort by providing them with a mission of their choice. This might be due to the fact that only a few subjects are motivated by one of the NGO missions. If that was the case and only the few motivated workers chose to work under NGO contracts, effort could be higher under those contracts. In this case sorting and screening of workers would be key, which leads us to Experiment II.

\section{Experiment II}

The choice of contracts in the first periods of Experiment II, with $p=5$, allows us to measure the willingness to pay to work under a contract for the preferred NGO. Table 4 shows the relative frequencies with which the different contracts are chosen. As long as the NGO contract pays more than the alternative contract, all subjects choose the NGO contract, which shows that nobody cares strongly more about the randomly selected student than the chosen NGO. However, when it becomes minimally costly to choose the NGO contract the majority of subjects chooses the alternative contract, which indicates that most subjects do not care much about the NGO donation either. $34 \%$ of the subjects (that is 24 out of 70) choose the NGO contract also when it is costly to do so. Some subjects are willing to pay $10 \mathrm{CHF}$ for the NGO contract and in the second session, in which we added a contract in period 14 with $p=5$ and a difference in fix wages of 40 points or $20 \mathrm{CHF}$, two subjects still choose the NGO contract at this price. However, not all subjects choose consistently, i.e., they choose the NGO in a later period where it is more expensive, while they do not in an earlier period. Therefore, we constructed different measures for the willingness to pay to work for the NGO. First, we took the biggest difference in fix wages a subject accepted in any of the periods with $p=5$. Second, we took the difference in fix wages in the period before a subject switched to the alternative contract for the first time. These measures can be thought of as upper and lower bounds for the willingness to pay. For the estimations reported in the paper we used the average of the two measures ${ }^{12}$

Regressing effort on the willingness to pay under the NGO contract, shows that effort significantly increases with the willingness to pay $(p<.05$, Model M2, Table 5$)$. This result also holds for different piece rates. Subjects with a positive willingness to pay also provide higher effort in the periods with piece rates different to $5(p<.05$, t-test, Model M5, Table A1 in the Appendix) ${ }^{13}$ Moreover, model M3 shows that, controlling for the contract type,

\footnotetext{
${ }^{12}$ The results change only minimally when the other measures are used.

${ }^{13}$ In model M6 (M7) the same specification was estimated for the periods with $p=7(p=3)$ separately (see Table A1 in the Appendix).
} 
Table 4: Contract Choices in First Periods of Experiment II

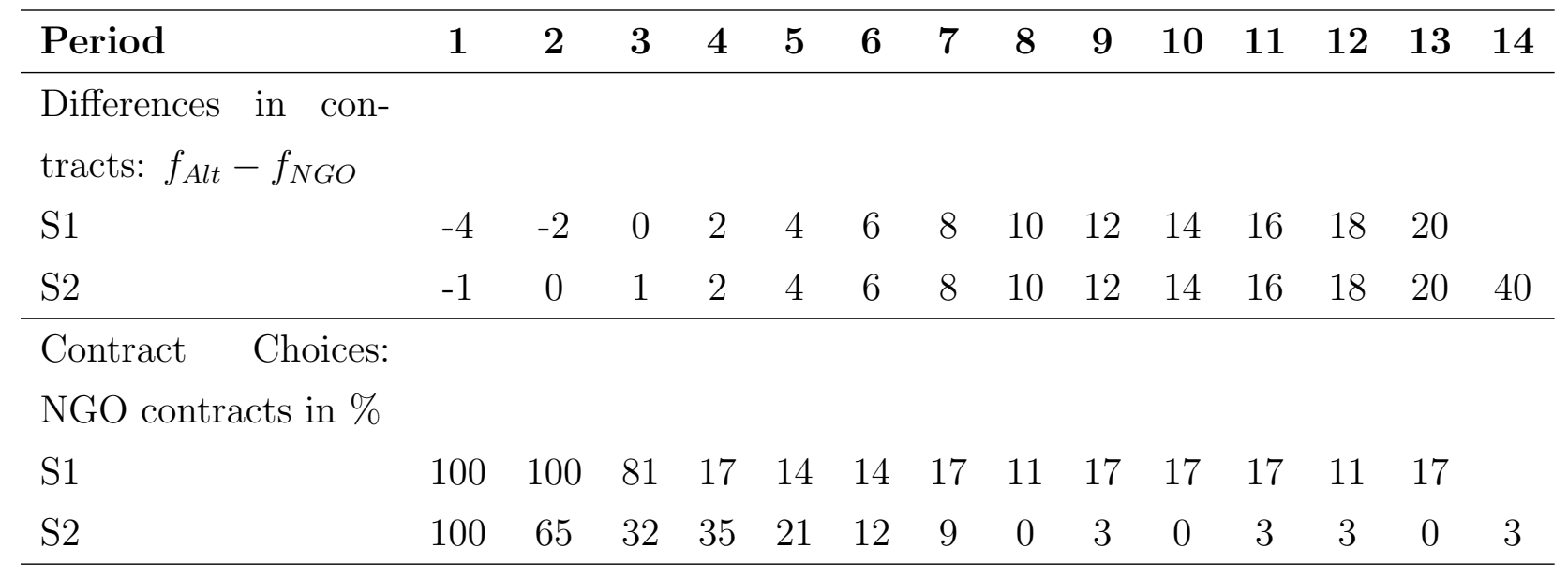

Note: S1 and S2 denote the sessions. The piece rate is unchanged in these periods, $p=5$.

the offered fix wage does not influence effort $(p>.5$, t-test).

The fact that effort increases with the willingness to pay implies that the lower the NGO wage is, compared to the alternative wage, the higher is effort provision of those who still choose to work under the NGO contract. Effort provision under NGO contracts of subjects with a willingness to pay of at least .5 CHF is 1.11 units higher than average effort provision under the alternative contract, 1.5 units higher for subjects with a willingness to pay of at least $3 \mathrm{CHF}, 2.1$ for those with a willingness to pay of at least $5 \mathrm{CHF}$, and 2.78 for those with a willingness to pay of at least $8 \mathrm{CHF}$.

Experiment II also allows us to do a robustness check of the results of Experiment I by comparing effort provision under an NGO contract with effort provision under an alternative contract within subjects. Given our choice of differences in fixed wages, we have observations under both types of contracts for 68 out of 70 subjects. Model M4 shows that subjects on average do not provide significantly higher effort under the NGO contract than under the alternative contract ( $p>.7$, t-test, Model M4, Table 5), thereby confirming our finding from the between subjects comparisons in Experiment I. The fix wage $f$ has again no effect on effort provision in this regression $(p>.5$, t-test).

The main finding of Experiment II is that there is a small subgroup of subjects that is willing to work for their preferred mission, even if this means to forgo monetary income, and this subgroup provides substantially higher effort. 
Table 5: Regression Models for Experiment II

\begin{tabular}{|c|c|c|c|c|c|c|}
\hline & \multicolumn{6}{|c|}{ Dependent variable: effort $e$} \\
\hline & \multicolumn{2}{|l|}{ M2 } & \multicolumn{2}{|l|}{ M3 } & \multicolumn{2}{|c|}{ M4 } \\
\hline & Coef & $\mathrm{SE}$ & Coef & $\mathrm{SE}$ & Coef & $\mathrm{SE}$ \\
\hline willingness to pay $\times$ NGO-contract & $.33^{* *}$ & .16 & $.33^{* *}$ & .16 & & \\
\hline willingness to pay & -.05 & .05 & -.05 & .05 & & \\
\hline NGO contract $[1 / 0]$ & -.19 & .31 & -.28 & .31 & .07 & .19 \\
\hline$f$ under chosen contract & & & -.01 & .01 & -.01 & .01 \\
\hline _cons & $10.25^{* * *}$ & .15 & $10.51^{* * *}$ & .34 & $10.52^{* * *}$ & .33 \\
\hline$\sigma$ & $1.97^{* * *}$ & .24 & $1.97^{* * *}$ & .24 & & \\
\hline$N$ & 944 & & 944 & & 944 & \\
\hline$N$ clusters & 70 & & 70 & & 70 & \\
\hline Pseudo- $R^{2}$ & .02 & & .02 & & & \\
\hline$R_{\text {within }}^{2}$ & & & & & $<.01$ & \\
\hline
\end{tabular}

\section{Conclusion}

Empirical evidence suggests that a part of the workforce is motivated by the missions of their jobs. This idea is also supported by theoretical arguments. Besley and Ghatak (2005) conclude that substantial efficiency gains might be feasible through improved matching of workers and employers with the right missions.

In this paper, we first ask the question whether a given group of workers can be motivated to provide higher effort by letting them choose the mission of their job. We test this in a laboratory experiment in which subjects can generate a donation to an NGO of their choice in addition to their monetary pay-off. In this setting, which should guarantee good matches of workers and missions, we do not observe increased effort provision. Tonin and Vlassopoulos (2010) find similar evidence. This suggests that improved matching of an existing workforce with their preferred missions, most likely, does not lead to a substantial increase in effort provision.

However, these results are at odds with empirical findings of high worker motivation in various organizations with strong missions (e.g., Carpenter and Knowles Myers 2010, Fehrler 2010, Gregg et al. 2011). Sorting might be the reason for these seemingly contradictory findings. Our second experiment shows that only about a third of the subjects is willing to give 
up monetary rewards for the option to generate a donation to their preferred NGO. These subjects, however, provide substantially higher effort. This suggests that a few individuals can, indeed, be motivated by the mission of their employer. Therefore, sorting of motivated workers into mission-oriented jobs is important, and offering a lower wage appears to be an effective screening device for employers with strong missions. These results are consistent with the empirical findings of both high motivation and low wages in mission-oriented organizations.

While this study focuses on the direct effect of missions on effort with and without selection, another more indirect link has also been discussed in the literature. Akerlof and Kranton (2005) argue that managements might be able to alter their workers' identity in order to make them internalize the goals of the organization. If this is true, and organizations with clear and strong missions are better able to make workers internalize their goals, this could also help explain why such organizations apparently have to pay lower wages than other employers to achieve a high level of effort. However, it is plausible that workers, who are already attracted somewhat by an organizational mission, would both tend to sort into this organization and be more willing to internalize the organizational goals. Hence, if internalization effects are important for effort provision outside the lab, sorting will still most likely be so, too. 


\section{References}

Akerlof, G. A., and R. E. Kranton (2005): "Identity and the economics of organizations," Journal of Economic Perspectives, 19(1), 9-32.

Besley, T., And M. Ghatak (2005): "Competition and Incentives with Motivated Agents," American Economic Review, 95, 616-636.

Brekke, K. A., And K. Nyborg (2008): "Attracting responsible employees: Green production as labor market screening," Resource and Energy Economics, 30(4), 509-526.

Burns, D. J., J. S. Reid, M. Toncar, J. Fawcett, and C. Anderson (2006): "Motivations to volunteer: The role of altruism," International Review on Public and Nonprofit Marketing, 3(2), 79-91.

Carpenter, J., and C. Knowles Myers (2010): "Why volunteer? Evidence on the role of altruism, image, and incentives," Journal of Public Economics, 94(11-12), 911 - 920.

DelfgaAuw, J., And R. DuR (2007): "Signaling and screening of workers' motivation," Journal of Economic Behavior \& Organization, 62(4), 605-624.

- (2008): "Incentives and Workers' Motivation in the Public Sector," The Economic Journal, 118(525), 171-191.

Dixit, A. (2002): "Incentives and Organizations in the Public Sector: An Interpretative Review," The Journal of Human Resources, 37(4), 696-727.

Fehrler, S. (2010): "Social Preferences, Sorting, and Signaling : An Experimental Analysis of Labor Market Processes," online available at: dissertationen.uzh.ch, University of Zurich.

FischBACHER, U. (2007): "z-Tree: Zurich toolbox for ready-made economic experiments," Experimental Economics, 10(2), 171-178.

Francois, P. (2000): “Public service motivation' as an argument for government provision," Journal of Public Economics, 78(3), 275-299.

Frank, S. A., And G. B. LeWIS (2004): "Government Employees. Working Hard or Hardly Working?," The American Review of Public Administration, 34(1), 36-51. 
Gerhards, L. (2012): "How (not) to incentivize motivated agents - An experiment with employees from a non-profit organization," Mimeo, Goethe University Frankfurt.

Gregg, P., P. A. Grout, A. Ratcliffe, S. Smith, and F. Windmeijer (2011): "How important is pro-social behaviour in the delivery of public services?," Journal of Public Economics, 95(7-8), 758 - 766.

Kosfeld, M., and F. A. von Siemens (2011): "Competition, cooperation, and corporate culture," The RAND Journal of Economics, 42(1), 23-43.

NyborG, K., And T. Zhang (2011): "Is corporate social responsibility associated with lower wages?," Memorandum 01/2011, Oslo University, Department of Economics.

Perry, J. L., A. Hondeghem, and L. R. Wise (2010): "Revisiting the Motivational Bases of Public Service: Twenty Years of Research and an Agenda for the Future," Public Administration Review, 70(5), 681-690.

Prendergast, C. (2007): "The Motivation and Bias of Bureaucrats," American Economic Review, 97(1), 180-196.

Tonin, M., And M. Vlassopoulos (2010): "Disentangling the sources of pro-socially motivated effort: A field experiment," Journal of Public Economics, 94(11-12), 1086 1092.

Twain, M. (1885): The Adventures of Huckleberry Finn, chap. 16. New York: Charles L. Webster. 


\section{Appendix}

Table A1: Robustness Checks for Periods with $p \neq 5$ in Experiment II

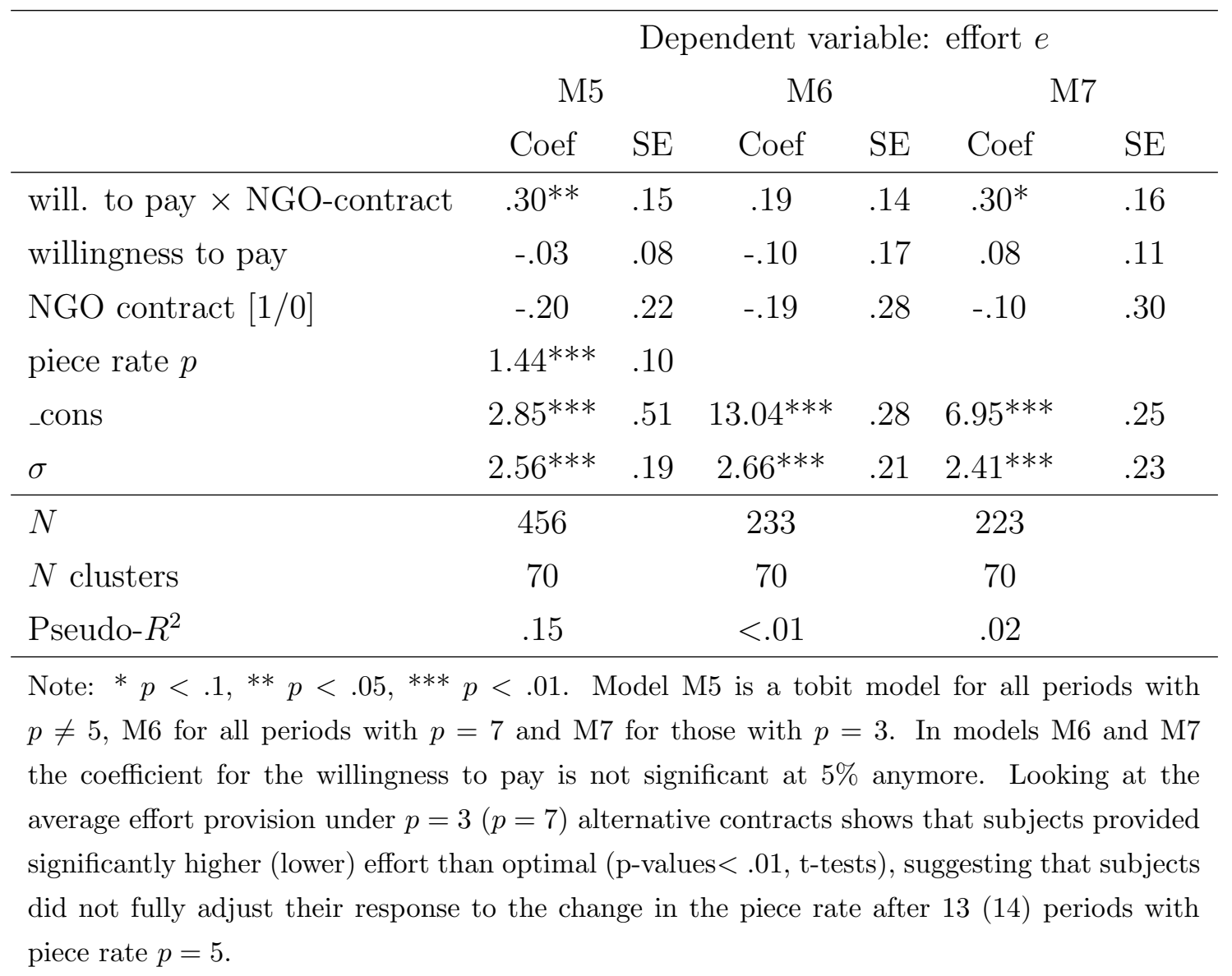


Table A2: Contracts in Experiment II

\begin{tabular}{|c|c|c|c|c|c|c|c|c|c|c|}
\hline \multicolumn{11}{|c|}{ Session 1} \\
\hline Period & 1 & 2 & 3 & 4 & 5 & 6 & 7 & 8 & 9 & 10 \\
\hline \multicolumn{11}{|c|}{ Piece rate } \\
\hline$p_{N G O}$ & 5 & 5 & 5 & 5 & 5 & 5 & 5 & 5 & 5 & 5 \\
\hline$p_{A l t}$ & 5 & 5 & 5 & 5 & 5 & 5 & 5 & 5 & 5 & 5 \\
\hline \multicolumn{11}{|l|}{ Fix wage } \\
\hline$f_{N G O}$ & 20 & 20 & 20 & 20 & 20 & 20 & 20 & 20 & 20 & 20 \\
\hline$f_{\text {Alt }}$ & 16 & 18 & 20 & 22 & 24 & 26 & 28 & 30 & 32 & 34 \\
\hline Period & 11 & 12 & 13 & 14 & 15 & 16 & 17 & 18 & 19 & 20 \\
\hline \multicolumn{11}{|c|}{ Piece rate } \\
\hline$p_{N G O}$ & 5 & 5 & 5 & 3 & 7 & 7 & 3 & 3 & 3 & 3 \\
\hline$p_{A l t}$ & 5 & 5 & 5 & 7 & 3 & 7 & 3 & 3 & 3 & 7 \\
\hline \multicolumn{11}{|l|}{ Fix wage } \\
\hline$f_{N G O}$ & 20 & 20 & 20 & 10 & 12 & 20 & 26 & 10 & 26 & 30 \\
\hline$f_{A l t}$ & 36 & 38 & 40 & 10 & 12 & 22 & 20 & 30 & 28 & 10 \\
\hline \multicolumn{11}{|c|}{ Different Contracts in Session 2} \\
\hline Period & 1 & 2 & 3 & 14 & & & & & & \\
\hline \multicolumn{11}{|c|}{ Piece rate } \\
\hline$p_{N G O}$ & 5 & 5 & 5 & 5 & & & & & & \\
\hline$p_{A l t}$ & 5 & 5 & 5 & 5 & & & & & & \\
\hline \multicolumn{11}{|l|}{ Fix wage } \\
\hline$f_{N G O}$ & 20 & 20 & 20 & 0 & & & & & & \\
\hline$f_{\text {Alt }}$ & 19 & 20 & 21 & 40 & & & & & & \\
\hline
\end{tabular}

Note: In periods 4-13 and 15-20 the contracts were the same in both sessions. 
[Instructions for Experiment I, treatment M-low]

Experiment: General Information for the “Employers”

You will now participate in a scientific experiment.

If you carefully read the following instructions, you can earn money. How much money you will earn depends on your decisions and decisions of other participants in the experiment. It is, therefore, important to read the instructions carefully.

Please, note that it is not permitted to communicate with other participants during the experiment. If you have questions, please, direct them at us.

At the beginning of the experiment all participants receive a show-up fee of 10 CHF. During the course of the experiment you can earn points in addition to that. All points you earn are converted into Swiss Francs at the end of the experiment. The exchange rate is:

\section{Point $=0.05$ CHF .}

At the end you receive the income you have earned during the experiment plus the $10 \mathrm{CHF}$ show-up fee in cash. You will be paid out in a separate room, so that no other participant can see how much you have earned. 


\section{The Experiment}

In this experiment there are always one employee and one employer in a group of two. None of the participants knows with whom they are in the same group, that is all decisions are made anonymously.

\section{You are an employer.}

At the beginning of the experiment all employees choose a Non-Governmental Organisation (NGO). You as an employer do not choose an NGO but you are informed about the choice of your employee. In the experiment the employee can, depending on his choices, generate a monetary donation for the NGO of his choice, in addition to his own pay-off.

The experiment consists of $\mathbf{1 0}$ periods. In each period you are in a group of two with the same employee. Every period is identical and proceeds as follows:

You, in the role of employer, offer a contract to your employee in each period. The contract consist of a fix wage and a bonus factor, which you chose. You can choose any integer between 0 and 100 points as fix wage. You can choose any integer between 0 and 12 as bonus factor. You make your decision on the following screen. On this screen, for example, the employee has chosen the NGO Attac Switzerland. 


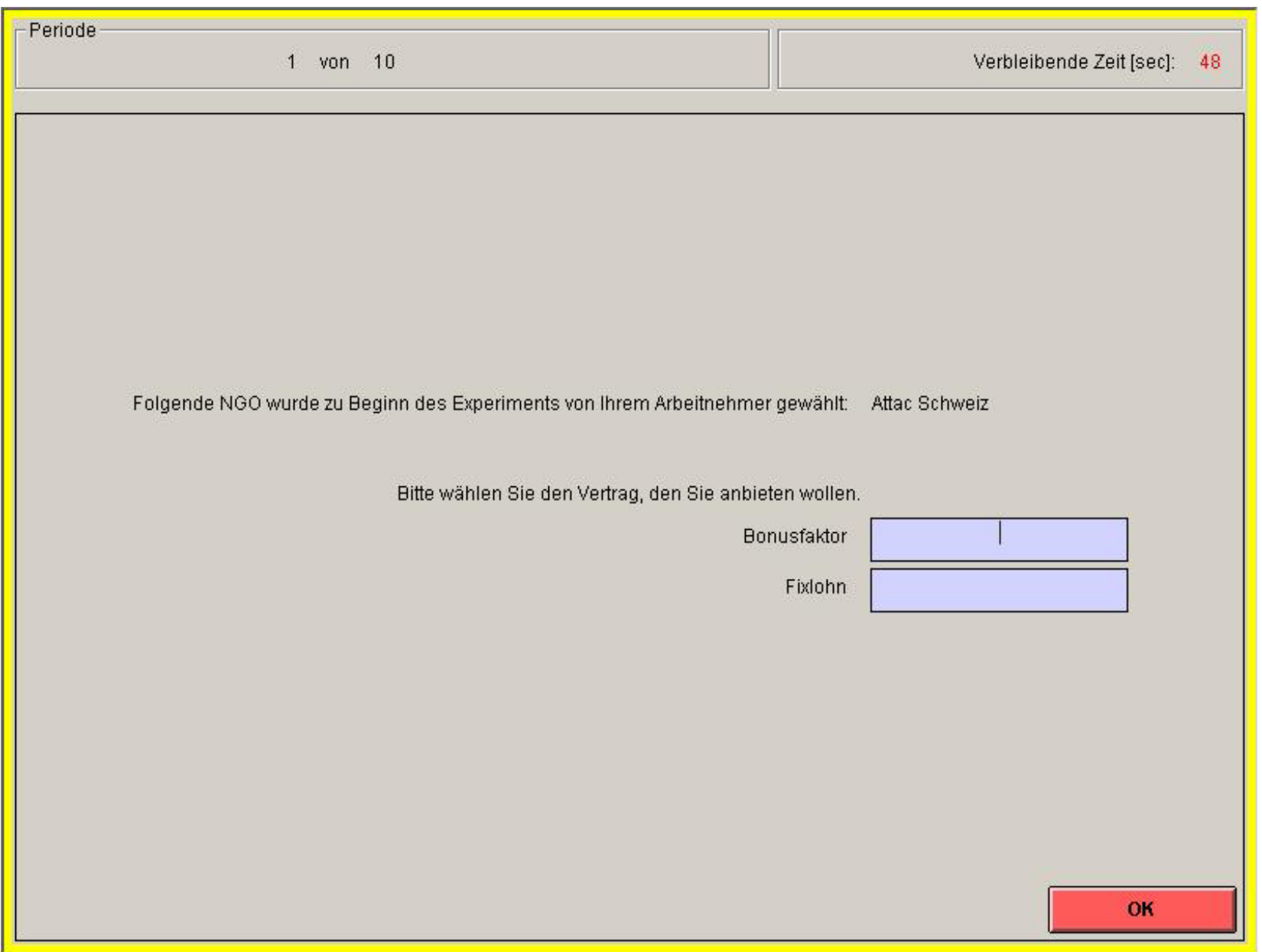

After you made your contract decisions, your offer will be transmitted to your employee, who then chooses his effort input, which is costly for him. The employee can choose any integer between 0 and 18 as effort input. The costs for every possible choice of effort are given in the following table: 


\begin{tabular}{|c|c|}
\hline $\begin{array}{c}\text { Effort choice of } \\
\text { the employee }\end{array}$ & Costs of effort in points \\
\hline 0 & 0 \\
\hline 1 & 0.25 \\
\hline 2 & 1 \\
\hline 3 & 2.25 \\
\hline 4 & 4 \\
\hline 5 & 6.25 \\
\hline 6 & 9 \\
\hline 7 & 12.25 \\
\hline 8 & 16 \\
\hline 9 & 20.25 \\
\hline 10 & 25 \\
\hline 11 & 30.25 \\
\hline 12 & 36 \\
\hline 13 & 42.25 \\
\hline 14 & 49 \\
\hline 15 & 56.25 \\
\hline 16 & 64 \\
\hline 17 & 72.25 \\
\hline 18 & 81 \\
\hline
\end{tabular}

Depending on the effort choice of your employee and your contract choice, the following incomes are realized for you and your employee:

Your income in one period

$10 *$ effort - fix wage - bonus factor*effort

Your income is determined by the choice of effort of your employee multiplied by 10, minus the wage that you pay, which consists of the fix wage and the bonus factor multiplied by the effort. 
Income of the employee in one period

Fix wage + bonus factor*effort - cost of effort +15

The income of your employee is determined by the wage that you pay (the fix wage plus the bonus factor multiplied by effort). From this the costs of effort are subtracted. A base income of 15 is added.

In addition to these incomes, each period, your employee generates a monetary donation to the NGO he has chosen. The level of the donation is determined by his effort. One unit of effort generates 1 point as a donation to the chosen NGO. If your employee, for example, chose an effort of 8 , the donation will be 8 points. The generated donations will be transferred to the NGOs at the end of the experiment. We will of course provide evidence for the transfers.

After all subjects have made their decisions, you start the next period with a new contract offer to your employee. In total, there are 10 periods. Your employee is the same in all periods. The income that you will be paid out at the end is the sum of the incomes from all 10 periods. Analogously, the total donation and the income of the employee are the sums over the ten periods. After the tenth period all totals will be displayed. Afterwards, your income will be paid out to you personally, that is without any other participant seeing how much you have earned, in cash. 


\section{Control Questions}

Please, answer the following control questions. Your answers do not influence the pay-offs of the experiment but only serve to check whether everybody understands the experiment. When you have finished, please, raise your hand, so that we can check your answers.

Question1: You are the employer. Suppose you offer your employee a fix wage of 3 and a bonus factor of 6 . He chooses an effort level of 10.

- How high is your income in this period?

- How high is the donation to the NGO in this period?

- How high is the employee's income in this period?

Question2: You are the employer. Suppose you offer your employee a fix wage of 0 and a bonus factor of 5 . He chooses an effort level of 12.

- How high is your income in this period?

- How high is the donation to the NGO in this period?

- How high is the employee's income in this period?

Question3: You are the employer. Suppose you offer your employee a fix wage of 10 and a bonus factor of 7. He chooses an effort level of 0 .

- How high is your income in this period?

- How high is the donation to the NGO in this period?

- How high is the employee's income in this period?

Question4: You are the employer. Suppose you offer your employee a fix wage of 5 and a bonus factor of 0 . He chooses an effort level of 6 .

- How high is your income in this period?

- How high is the donation to the NGO in this period?

- How high is the employee's income in this period?

Do you have any questions? 
Experiment: General Information for the "Employees”

You will now participate in a scientific experiment.

If you carefully read the following instructions, you can earn money. How much money you will earn depends on your decisions and decisions of other participants in the experiment. It is, therefore, important to read the instructions carefully.

Please, note that it is not permitted to communicate with other participants during the experiment. If you have questions, please, direct them at us.

At the beginning of the experiment all participants receive a show-up fee of 10 CHF. During the course of the experiment you can earn points in addition to that. All points you earn are converted into Swiss Francs at the end of the experiment. The exchange rate is:

\section{Point $=0.05$ CHF .}

At the end you receive the income you have earned during the experiment plus the $10 \mathrm{CHF}$ show-up fee in cash. You will be paid out in a separate room, so that no other participant can see how much you have earned. 


\section{The Experiment}

In this experiment there are always one employee and one employer in a group of two. None of the participants knows with whom they are in the same group, that is all decisions are made anonymously.

\section{You are an employee.}

At the beginning of the experiment all employees choose a Non-Governmental Organisation (NGO). The list of all NGOs that you can choose from is displayed below. In the experiment you can, depending on your choices, generate a monetary donation for the NGO of your choice, in addition to your own pay-off. The donation will be transferred to the NGO after this study is completed. More details on how the level of donation is determined follows below. The subjects in the role of employer do not choose an NGO.

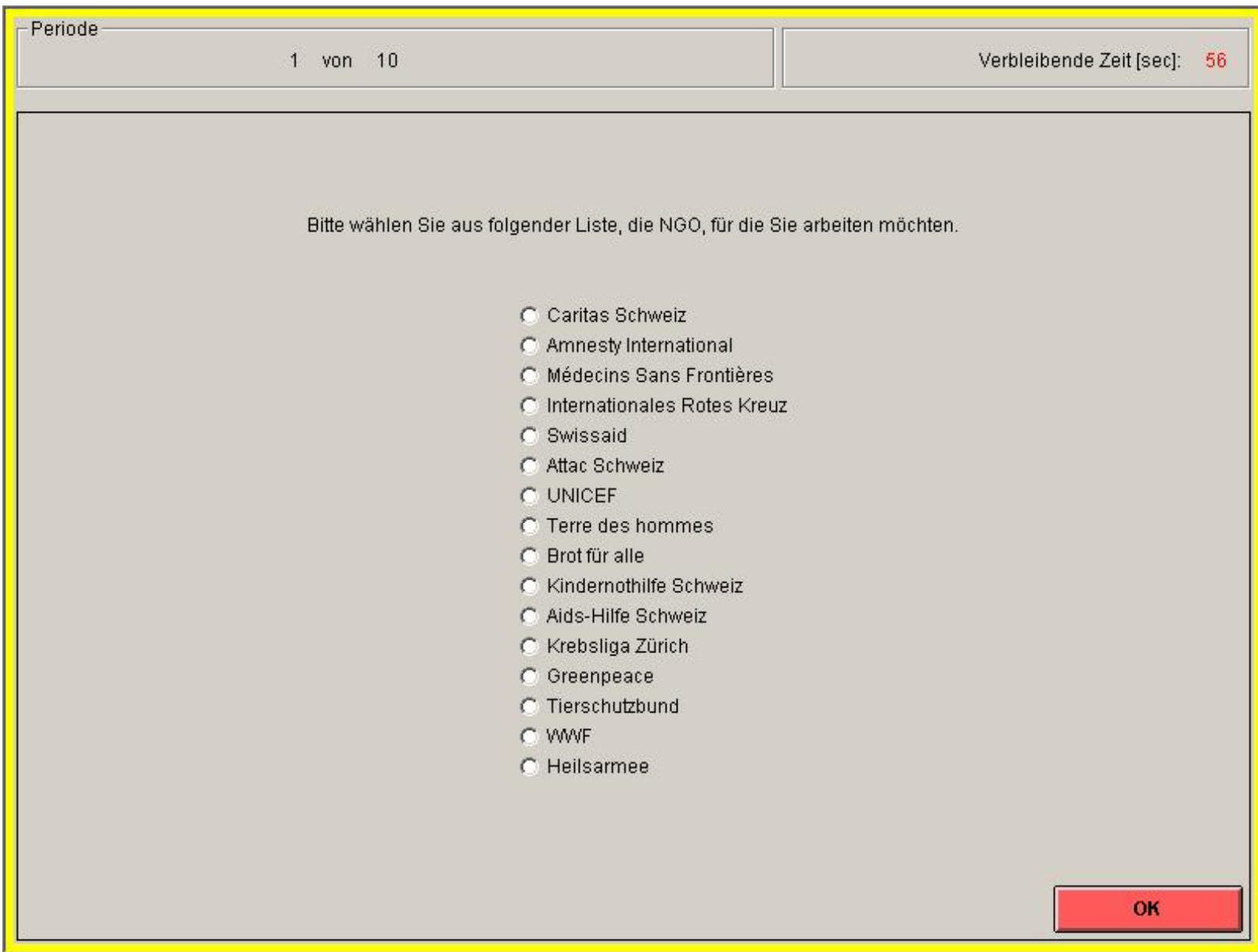


The experiment consists of $\mathbf{1 0}$ periods. In each period you are in a group of two with the same employer. Every period is identical and proceeds as follows:

In each period you receive a base income of 15 points. On top of this you can earn further points. At first your employee offers you a contract in each period. The contract consists of a fix wage and a bonus factor. As fix wage any integer between 0 and 100 points can be chosen. As bonus factor any integer between 0 and 12 can be chosen.

After your employer has made the contract decisions, his offer will be transmitted to you. Then you can choose your effort input. You make your decision on the following screen.

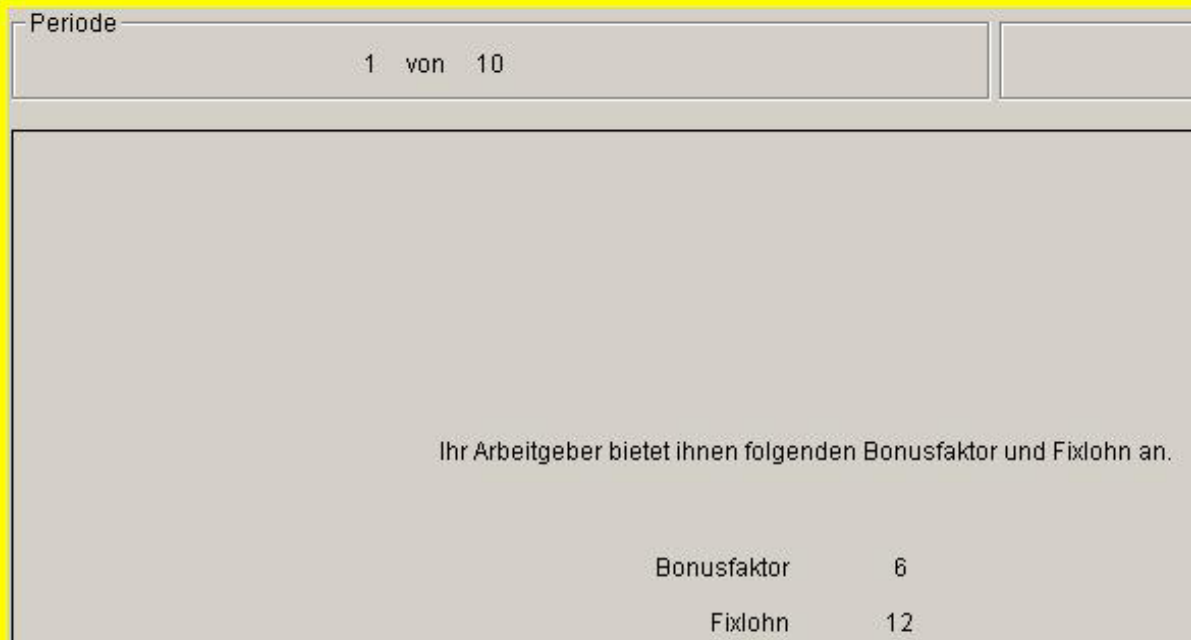

Wählen Sie nun Ihren Arbeitseinsatz

Arbeitseinsatz

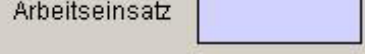

On this screen, for example, your employer offered you a bunus factor of 6 and a fix wage of 12 points. Please, enter your choice of effort in the according interface and confirm you decision by pressing the "OK" button. As effort you can choose any integer between $\mathbf{0}$ and 18. 
Your choice of effort is associated with a cost. The costs in terms of points are presented in the following table.

\begin{tabular}{|c|c|}
\hline Effort choice & Costs of effort in points \\
\hline 0 & 0 \\
\hline 1 & 0.25 \\
\hline 2 & 1 \\
\hline 3 & 2.25 \\
\hline 4 & 4 \\
\hline 5 & 6.25 \\
\hline 6 & 9 \\
\hline 7 & 12.25 \\
\hline 8 & 16 \\
\hline 9 & 20.25 \\
\hline 10 & 25 \\
\hline 11 & 30.25 \\
\hline 12 & 36 \\
\hline 13 & 42.25 \\
\hline 14 & 49 \\
\hline 15 & 56.25 \\
\hline 16 & 64 \\
\hline 17 & 72.25 \\
\hline 18 & 81 \\
\hline
\end{tabular}

Depending on your effort choice and the contract chosen by your employer, the following incomes are realized for you and your employer:

\section{Your income in one period}

Fix wage + bonus factor*effort - cost of effort +15

One part of your income is your wage. This is the fix wage chosen by your employer plus the bonus factor multiplied by your effort. From this the costs of effort are subtracted. Finally, your base income of 15 is added. 
Income of the employer in one period

$10^{*}$ effort - fix wage - bonus factor*effort

The income of your employer is determined by your choice of effort multiplied by 10, minus the wage that he pays you (consisting of the fix wage and the bonus factor multiplied by the effort).

In addition to these incomes, each period, you generate a monetary donation to the NGO you have chosen. The level of the donation is determined by your effort. One unit of effort generates 1 point as a donation to the chosen NGO. If you, for example, choose an effort of 8 , the donation will be 8 points. The generated donations will be transferred to the NGOs at the end of the experiment. We will of course provide evidence for the transfers.

After all subjects have made their decisions, the next period starts with a new contract offer from your employer. In total, there are 10 periods. Your employer is the same in all periods. The income that you will be paid out at the end is the sum of the incomes from all 10 periods. Analogously, the total donation and the income of the employer are the sums over the ten periods. After the tenth period all totals will be displayed. Afterwards, your income will be paid out to you personally, that is without any other participant seeing how much you have earned, in cash. 


\section{Control Questions}

Please, answer the following control questions. Your answers do not influence the pay-offs of the experiment but only serve to check whether everybody understands the experiment. When you have finished, please, raise your hand, so that we can check your answers.

Question1: You are the employee. Suppose your employer offers you a fix wage of 3 and a bonus factor of 6. You choose an effort level of 10.

- How high is your income in this period?

- How high is the donation to the NGO in this period?

- How high is the employer's income in this period?

Question2: You are the employee. Suppose your employer offers you a fix wage of 0 and a bonus factor of 5. You choose an effort level of 12.

- How high is your income in this period?

- How high is the donation to the NGO in this period?

- How high is the employer's income in this period?

Question3: You are the employee. Suppose your employer offers you a fix wage of 10 and a bonus factor of 7. You choose an effort level of 0 .

- How high is your income in this period?

- How high is the donation to the NGO in this period?

- How high is the employer's income in this period?

Question4: You are the employee. Suppose your employer offers you a fix wage of 5 and a bonus factor of 0 . You choose an effort level of 6 .

- How high is your income in this period?

- How high is the donation to the NGO in this period?

- How high is the employer's income in this period?

Do you have any questions? 
[Instructions for Experiment II]

General Information

You will now participate in a scientific experiment.

If you carefully read the following instructions, you can earn money. How much money you will earn depends on your decisions and decisions of other participants in the experiment. It is, therefore, important to read the instructions carefully.

Please, note that it is not permitted to communicate with other participants during the experiment. If you have questions, please, direct them at us.

At the beginning of the experiment all participants receive a show-up fee of 10 CHF. During the course of the experiment you can earn points in addition to that. All points you earn are converted into Swiss Francs at the end of the experiment. The exchange rate is:

\section{Point $=0.5$ CHF .}

At the end you receive the income you have earned during the experiment plus the $10 \mathrm{CHF}$ show-up fee in cash. You will be paid out in a separate room, so that no other participant can see how much you have earned. 


\section{The Experiment}

In this experiment all participants are employees and work under different contracts. Under some contracts they work for a Non-Governmental Organization (NGO) of their choice, under the other contracts for a randomly chosen student of the University of Zurich.

In the beginning of the experiment every employee chooses an NGO. The list of NGOs you can choose from is displayed below. Through your decisions in the experiment you can - in addition to your personal income - generate a monetary donation to your chosen NGO or for a randomly chosen student of the University of Zurich. The donation will be paid out to the according NGO or the student when this study is completed. More details on how the level of donation is determined follows below.

Bitte wählen Sie aus folgender Liste, die NGO, für die Sie arbeiten möchten.

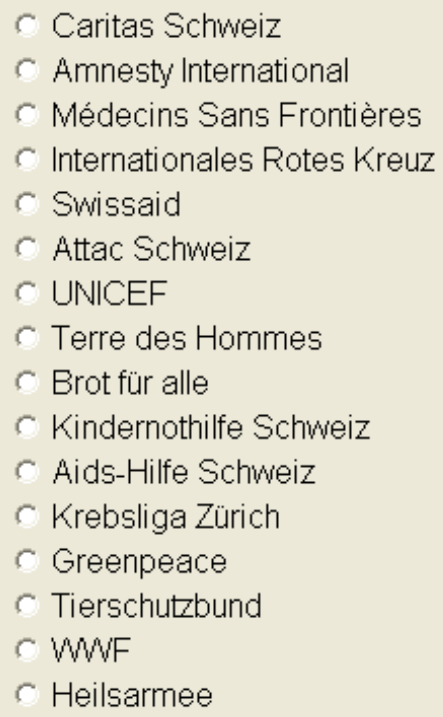

The experiment consists of $\mathbf{2 0}$ periods, out of which one is randomly chosen at the end and paid out according to your decisions. Every period is identical and proceeds as follows:

You are offered two contracts each period out of which you have to choose one. Every contract consists of a fix wage and a bonus factor. After choosing a contract, you can choose your level of 
effort that you want to provide under that contract. The decisions about your contract choice and effort provision are made on the following screen.

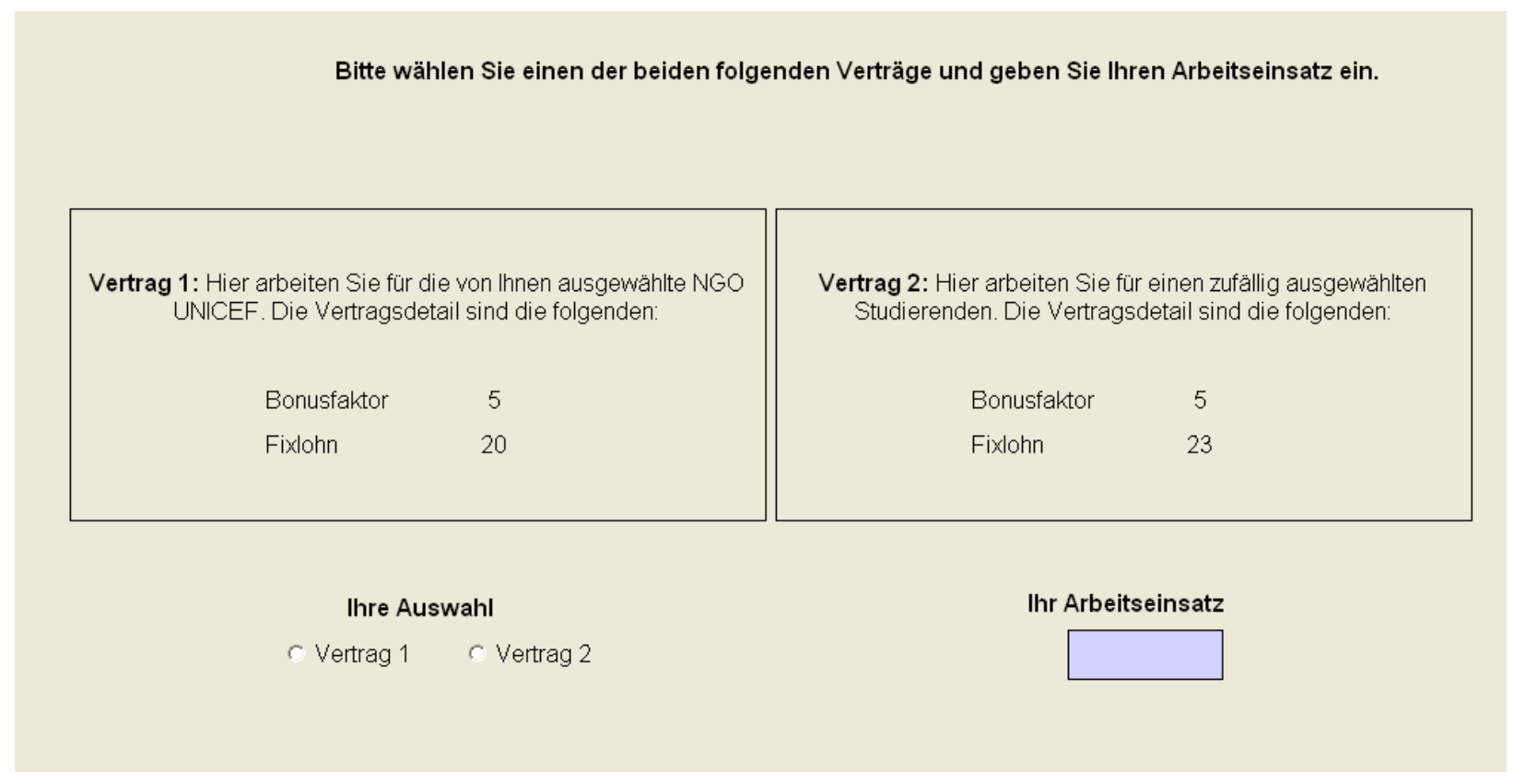

On this screen, you are offered a contract 1 with a fix wage of 20 and a bonus factor of 5 , as well as a contract 2 with a bonus factor of 5 and a fix wage of 23. Under contract 1 you work for your chosen NGO (in this example UNICEF), which means, that a donation to this NGO is generated, in addition to your income. Under contract 2 you work for a randomly chosen student of the University of Zurich, which means, that a donation to this student is generated, in addition to your income.

Please, choose one of the contracts and enter your effort level in the according interface. As effort level you can choose any integer between 0 and 18. 
Your choice of effort is associated with a cost. The costs in terms of points are presented in the following table.

\begin{tabular}{|c|c|}
\hline Effort choice & Costs of effort in points \\
\hline 0 & 0 \\
\hline 1 & 0.25 \\
\hline 2 & 1 \\
\hline 3 & 2.25 \\
\hline 4 & 4 \\
\hline 5 & 6.25 \\
\hline 6 & 9 \\
\hline 7 & 12.25 \\
\hline 8 & 16 \\
\hline 9 & 20.25 \\
\hline 10 & 25 \\
\hline 11 & 30.25 \\
\hline 12 & 36 \\
\hline 13 & 42.25 \\
\hline 14 & 49 \\
\hline 15 & 56.25 \\
\hline 16 & 64 \\
\hline 17 & 72.25 \\
\hline 18 & 81 \\
\hline
\end{tabular}

Depending on your choice of effort and the chosen contract your income is determined as follows:

Your income in one period (in points)

Fix wage + bonus factorxeffort - costs of effort

One part of your income is your wage. This is the fix wage plus the bonus factor multiplied by your effort. From this the costs of effort are subtracted.

In addition to these incomes, each period, you generate a monetary donation to either NGO you have chosen or a randomly chosen student of the University of Zurich, depending on your contract choice. The level of the donation is determined by your effort. One unit of effort generates 1 point as a donation to the chosen NGO or the randomly chosen student. If you, for example, chose an effort of 8 , the donation will be 8 points. After all participants have made their choices, the next period begins. 
Not all the periods are paid out. One period will be chosen randomly at the end and your income and the donation will be determined by your decisions in that period. The generated donation will be transferred to the NGO or the student at the end of this study. ${ }^{*}$ Your income will be paid out to you personally, that is without any other participant seeing how much you have earned, in cash at the end of the experiment.

[Note: In this experiment, unlike the first, the quiz was part of the zTree program and the subjects did it on their screens.]

*You can have a look at the transfer receipts if you wish. Contact Mrs. Monika Noser [email address] of the secretariat of the Department of Political Science for this purpose. 